Nordisk Tidsskrift for Kriminalvidenskab 2008

\title{
FÅnGTAL OCH BROTT - HuR SER SAMBANDET UT?
}

\section{Av docent Peter Lindström}

Will an increase in prison populations reduce crime? According to most criminologists, the answer is probably no. But if the same question is posed to an economist, the answer received will most likely be yes. From a crime policy perspective, values rather than evidence are the primary guide. Most studies of the relationship between rates of imprisonment and crime use observational data, analysed with some type of time-series analysis. A review of the empirical criminological literature tends to reveal a negative statistical association between prison population and crime at the aggregate level. However, at the individual level, the association is often found to be positive, i.e. imprisonment is deleterious for the inmate and his family. The finding of a statistical association is, of course, no proof of a causal relationship, since the two may co-vary as a function of other circumstances. Data from four Scandinavian countries for the years 1990-2005 indicate a negative correlation between rates of imprisonment and lethal violence. Likewise, a second analysis finds that the monthly imprisonment rate is negatively related to the monthly burglary rate in Sweden. The conclusions of these analyses are, however, less than straight forward. First, changes in the imprisonment rate are determined by political decisions. Second, the collateral effects of imprisonment on re-offending, as well as on individual economic and social well-being, are fairly well known. Third, even where evidence for a negative relationship between rates of imprisonment and crime are shown, the fundamental question as to whether this relationship is causal remains unanswered."

"Facts do not organize themselves into concepts and theories just by being looked at; indeed, except within the framework of concepts and theories, there are no scientific facts but only chaos. Question must be asked before answers can be given. The questions are all expressions of our interest in the world; they are at bottom valuations" (Myrdal, 1969, s. 9).

\section{Inledning}

Fängelsestraff är en universell påföljd vid allvarligare brott. De flesta är nog överens om att fängelser behövs. Men frågan är till vad? För vilka brott ska ett fängelsestraff dömas ut och hur länge ska gärningsmannen sitta instängd? Vilken betydelse ska återfall $\mathrm{i}$ brott ha när ett eventuellt fängelsestraff kan komma ifråga? Den kanske vanligaste frågan - vilka effekter har fängelsestraff på brottsligheten - är åter aktuell

\footnotetext{
- Title in English: Rates of Imprisonment and Crime: What is their Association? Original in Swedish.
} 
inom den kriminologiska forskningen. Enkelt sammanfattat kan tre slutsatser om detta samband hittas i forskningslitteraturen: fängelsestraffet har (i) ingen effekt på brottsligheten, (ii) ökar brottsligheten respektive (iii) minskar brottsligheten.

I sig är det givetvis inte särskilt märkligt att empiriska studier kommer till olika slutsatser, såväl tidsperioder som geografiska områden och inte minst tillvägagångssätt och metodval har ofta betydelse för resultaten. Problem uppstår däremot när personliga uppfattningar och värderingar påverkar forskningsresultaten. Detta tillkortakommande tycks finnas hos såväl förespråkare som kritiker av fängelsestraffet. Ett problem av mer vetenskapsteoretisk natur är frågan om det går att göra kausala tolkningar utifrån observationsdata. ${ }^{1}$ Det finns av naturliga skäl få studier av sambandet mellan fängelsestraff och brott som baseras på en experimentdesign, forskarna är som regel hänvisade till observations- eller simuleringsdata genererade från teoretiska modeller (som förvisso kan ha en empirisk bas). Genom vissa analystekniska tillvägagångssätt går det emellertid att stärka möjligheten att göra tolkningar som kan peka mot ett kausalt samband, exempelvis genom att analysera sambandet mellan fängelsestraff vid en given tidpunkt och brottslighet vid en annan, senare, tidpunkt.

För att studera effekter av fängelsestraff på brottsligheten finns i huvudsak två tillvägagångssätt. För det första har forskning sedan mitten av 1970-talet försökt att beräkna hur många brott som en person som avtjänar ett fängelsestraff skulle ha begått om han inte suttit inlåst. Den brottslighet som förebyggs genom inlåsningen brukar kallas inkapaciteringseffekt. Metoder för att skatta inkapaciteringseffekter baseras vanligtvis på individdata där simuleringar görs för att beräkna hur många brott som teoretiskt skulle förhindras om fängelsestraffet ökar (eller minskar) med viss tid (Ahlberg, 1990; Andersson, 1991). Piquero och Blumstein (2007) har nyligen sammanfattat forskning om inkapaciteringseffekter och utifrån deras sammanställning kan man dra slutsatsen att en tioprocentig ökning av fångpopulationen medför en tvåprocentig minskning av brottsligheten. ${ }^{2}$ Ett annat sätt att beskriva den så kallade elasticiteten mellan fångpopulation och brottslighet är att en fördubbling av antalet fängelsedömda skulle medföra att brottsligheten minskar med en femtedel.

Det andra sättet att studera effekter av fängelsestraff på brottsligheten utgår från att det förutom inkapaciteringseffekter också kan finnas en generellt avskräckningseffekt av detta straff. Med hjälp av data på aggregerad nivå jämförs över tid och/eller mellan olika geografiska enheter sambandet mellan fångpopulation och brottsnivåer. Miles och Ludwig (2007) menar att skattningar av inkapaciteringseffekter i det närmaste är ett omöjligt projekt eftersom metoden utgår från ett stort antal svårtestade antaganden och inte minst kräver data som sällan finns tillgängliga. Enligt Miles och Ludwig ger som regel ekonometriska analysmetoder ett bättre beslutsunderlag om fängelsestraffets inverkan på brottsligheten. Deras 
tolkning av denna forskning är att en tioprocentig ökning av fångpopulationen ger en fyraprocentig minskning av brottsligheten eller med andra ord en fördubbling av fångpopulationen minskar brottsligheten med 40 procent.

Under de senaste 10-15 åren har forskning om effekter av fängelsestraff på brottsligheten ökat i omfattning. Den absoluta merparten av denna forskning kommer från USA vilket delvis kan förklaras av att fångpopulationen där under de senaste tre decennierna har fyrdubblats och sedan början av 1990-talet har även den registrerade brottsligheten minskat. Hur ser sambandet ut mellan fångpopulations utveckling och brottsligheten i Sverige och övriga norden? Syftet med denna artikel är att närmare analysera denna frågeställning $\mathrm{i}$ två analyser. För det första analyseras sambandet mellan fångpopulationens storlek och utvecklingen av dödligt våld $\mathrm{i}$ de nordiska länderna för åren 1990-2005. För det andra analyseras sambandet mellan antalet fängelsedömda och antalet anmälda bostadsinbrott per månad i Sverige för två perioder, januari 1975 - december1990 respektive januari 1994 - juni 2007. Artikeln avslutas med diskussion om vilket betydelse en förändrad åldersammansättning bland fängelsedömda kan tänkas ha för detta samband. Inledningsvis presenteras en sammanfattning av aktuell forskning om sambandet mellan fångtal och brott.

\section{Forskning om fängelsestraff, fångtal och brottslighet}

Kriminologer $\mathrm{i}$ allmänhet har under långt tid ifrågasatt om fängelsestraff över huvud taget har några effekter på brottsligheten. Uppfattningen tycks snarare vara att: "One of the established truth among today's criminologists and sociologists is that the prison is a fiasco" (Nilsson, 2003, s. 2). Skandinaviska kriminologer tycks vara överens med von Hofer (2007) om att "... the use of custodial sentences does not constitute an effective crime policy tool for the management of societal crime levels".

Vid Stockholm Criminology Symposium 2007 presenterade den amerikanske kriminologiprofessorn Daniel Nagin en analys av sannolikheten för återfall i brott bland personer dömda till fängelse i Nederländerna jämfört med en matchad kontrollgrupp. ${ }^{3}$ Analysen visar att: "For those who are a little older at the time of a first conviction... [i]t is the negative effects of a prison sentence that appear to weigh heaviest" (Brå, 2007, s. 10). Enkelt sammanfattat fann Nagin att återfall i ny brottslighet var signifikant högre bland personer över 25 år som dömts till fängelse jämfört med kontrollgruppen.

Spohn (2007) och Spohn och Holleran (2002) har redovisat analyser av drygt 1000 personer dömda för grövre brott i Kansas City och som följdes upp under en fyraårsperiod. Den frågeställning som testades var om personer dömda till fängelse återföll i mindre utsträckning än personer dömda till övervakning (probation). Svaret är ett entydigt nej. Resultatet visar snarare att gruppen fängelsedömda 
återfaller i högre utsträckning och snabbare efter avtjänat straff än gruppen som dömdes till "probation". Jämförelsen mellan dessa två grupper är inte baserad på ett randomiserat experiment men i den statistiska analysen tas hänsyn till såväl demografiska som sociala variabler och andra individuella bakgrundsfaktorer.

Tolkningen av resultaten ovan är att fängelsestraffet i sig ökar risken för återfall i brott genom exempelvis social inlärning, stigmatisering eller försvagade sociala band till det konventionella samhället. ${ }^{4}$ Enligt Liebling och Maruna (2005, s. 18) kan: "Imprisonment weakens these (already vulnerable) bonds, and makes them difficult to re-establish, hence severing a significant source of legitimate or law-abiding behaviour. Imprisonment thereby becomes a part of the cycle of delinquency and crime".

Nya forskningsanalysen - men på två äldre datamaterial ${ }^{5}$ - har också visat att fängelsestraffet inte bara kan vara negativt för den dömde; även den dömdes barn löper större risk än andra att själva bli kriminella i tonåren och tidig vuxenålder. I en komparativ studie mellan Sverige och England fann Murray m.fl. (2007) att om en förälder (vanligtvis fadern) hade avtjänat ett fängelsestraffet så hade det i sig en statistiskt signifikant effekt på barnets egen brottslighet upp till 18 års åldern, även när man tog hänsyn till förälderns samtliga registrerade brott. Denna effekt framkom däremot inte i Sverige, även om det föreligger ett samband mellan föräldrarnas och deras barns brottslighet. En tolkning av detta resultat är att:

\footnotetext{
"In Sweden, the combination of shorter prison sentences, prison policies that encouraged family contact, the advanced social welfare system, welfare-oriented juvenile justice policies, and sympathetic public attitudes towards criminal offenders could have protected children from harmful effects of parental incarceration" (Murray m fl, 2007, s. 147).
}

Genomgången av forskningslitteraturen skulle kanske redan här kunna avslutas med slutsatsen att fängelsestraff har inga eller möjligen skadliga effekter på brottsligheten. Om det inte vore för ett flertal uppmärksammade studier genomförda de senaste 10-15 åren framför allt av nationalekonomer.

Amerikanska ekonomer som arbetar på det kriminologiska området, exempelvis Marvell och Moody (1994; 1997), Levitt (1996; 2004) och Becsi (1999), hävdar att brottsminskningen i USA sedan början av 1990-talet till rätt så stor del beror på ökningen av antalet fängelsedömda. Detta resultat "krockar" således med traditionell kriminologisk forskning. En gemensam uppfattning från båda sidor om denna forskningsfråga tycks emellertid vara att fångpopulationen i huvudsak påverkas av politiska beslut och endast i marginell utsträckning är ett resultat av förändringar av brottsligheten. För en beskrivning av hur politiska beslut påverkar fångpopulationens storlek se Lappi-Seppälä (2000) respektive von Hofer (2003). Enligt Jacobson (2006) är det framför allt budgetpolitiken som styr utbyggnaden av fängelsekapaciteten. 
I en analys av sambandet mellan dödligt våld och fångpopulationens storlek i USA för perioden 1930-1994 drar Marvell och Moody (1997) slutsatsen att en 10-procentig ökning av fångtalet medför att antalet mord minskar med igenomsnitt 13 procent. Denna slutsats står sig även när de analyserar materialet uppdelat för perioden 1930-1962 respektive 1962-1994. I den första perioden ger en 10-procentig ökning av fångpopulationen en 9-procentig minskning av det dödliga våldet medan minskningen i den senare perioden blir 15 procent. Även för polisanmäld misshandel och rån framkommer statistiskt signifikanta negativa effekter av fångpopulation.

Marvell och Moodys resultat - eller åtminstone storleken på deras uppmätta effekt - har ifrågasatts av andra ekonomer (exempelvis av Levitt, 2001, s. 379). I en utvärdering av tre specifika polisrelaterade projekt konstaterar emellertid Rosenfeld m.fl. (2005, s. 435) att: "the growth in incarceration during the 1990s is consistently related to the homicide trends examined in this study. We cannot rule out entirely the possibility that Compstat, and perhaps Ceasefire and Exile, had an indirect effect on homicide through incarceration. Conceivably, the programs increased state prison sentences that, in turn, reduced homicide rates".

Även mer renodlade kriminologer har konstaterat sambandet mellan fångtal och brott. I en omfattande meta-analys av vilka samhällsfaktorer som har samband med brottslighet fann Pratt och Cullen (2005) att fängelsestraff har en jämförelsevis stark och stabil negativ effekt på brottsligheten. Det vill säga när fångpopulation ökar så minskar brottslighet. Variabler som verkar i motsatt riktning är exempelvis fattigdom, splittrade familjer och andel av befolkningen som tillhör etniska minoriteter. Andra faktorer på den repressiva sidan, till exempel fler poliser och intensifierade polisiära strategier mot brott, visade sig ha betydligt svagare och mindre stabila effekter. Sammantaget varnar därför Pratt och Cullen (2005, s. 437) för att alltför ensidigt tro att rättsväsendets insatser kan förebygga brott i någon större omfattning.

Inte oväntat kommer emellertid forskning som i huvudsak använder samma typ av statistiska metoder till helt olika slutsatser. I artikeln "Jobs or Jails? The Crime Drop in Texas" konstaterar Spelman (2005, s. 162) att: "Texas' primary respons to the crime problem - massive incarceration - worked". Detta resultat kan ställas mot Kovandzic och Vieraitis (2006, s. 234) slutsats från analyser av detta samband för Florida: "This study finds no support for the "more prisoners, less crime" thesis". Vad skiljer dessa undersökningar åt förutom delstater? 
Tabell 1. En jämförelse av två nyligen publicerade amerikanska undersökningar

\begin{tabular}{|c|c|c|}
\hline & Spelman (2005) & $\begin{array}{l}\text { Kovandzic och } \\
\text { Vieraitis (2006) }\end{array}$ \\
\hline Period & $1990-2000$ & $1980-2000$ \\
\hline Plats & Texas & Florida \\
\hline Antal "counties" & 254 & 58 \\
\hline Antal observationer & 2540 & 1156 \\
\hline Polisanmäld brottslighet & $\begin{array}{l}\text { Violence resp. property } \\
\text { (violence: mord, våldtäkt, rån, } \\
\text { grov misshandel. Property: } \\
\text { inbrott, grov stöld, biltillgrepp) }\end{array}$ & $\begin{array}{l}\text { Uppdelad på de sju } \\
\text { indexbrotten (mord, văldtäkt, } \\
\text { rån, grov misshandel, inbrott, } \\
\text { grov stöld och biltillgrepp) }\end{array}$ \\
\hline $\begin{array}{l}\text { Definition av variabeln } \\
\text { "prison population" }\end{array}$ & $\begin{array}{l}\text { State prisoners and local jail } \\
\text { inmates on } 31 \text { December } \\
\text { who were accused or } \\
\text { convicted of crimes } \\
\text { committed in that county } \\
\text { per } 1000 \text { county residents }\end{array}$ & $\begin{array}{l}\text { The number of inmates who } \\
\text { had been sentenced in the } \\
\text { county to more than one year } \\
\text { in prison under state prison } \\
\text { jurisdiction on June } 30 \text { th } \\
\text { and is expressed in rates per } \\
100000 \text { resident population }\end{array}$ \\
\hline Logaritmerade variabler & $\mathrm{Ja}$ & $\mathrm{Ja}$ \\
\hline Differentierade variabler & $\mathrm{Ja}$ & Nej \\
\hline Antal kontrollvariabler & 28 & 10 \\
\hline Instrument-variabler & Ja & Nej \\
\hline $\begin{array}{c}\text { Effekt av "prison } \\
\text { population" på "crime" }\end{array}$ & $\begin{array}{l}\text { Interaktion mellan } \\
\text { variablerna "inmate } \\
\text { population" och "metro": } \\
\text { violence: }-0.24^{*} \\
\text { property: }-0.25^{*}\end{array}$ & $\begin{array}{c}\text { Homicide: }-0.06 \\
\text { Rape: }-0.13 \\
\text { Robbery: }-0.07 \\
\text { assault: }-0.00 \\
\text { Burglary: }-0.08 \\
\text { Larency: }-0.08 \\
\text { Auto theft: }-0.07\end{array}$ \\
\hline
\end{tabular}

En närmare jämförelse mellan dessa två studier visar på subtila men betydande skillnader. Som mått på fångpopulationen använder Spelman samtliga intagna på häkte eller fängelse misstänkta eller dömda för brott medan Kovandzic och Vieraitis har begränsat sin analys till samtliga intagna i delstatsfängelser (prison) och som därmed har en strafftid på minst ett år. Detta har givetvis betydelse för analysen. Å andra sidan har Kovandzic och Vieraitis en längre tidsperiod jämfört med Spelman medan den senare har betydligt fler kontrollvariabler. Utifrån ett ekonometrisk perspektiv är Spelmans analys mer komplex eftersom den tar hänsyn till att brottsligheten också kan påverka fångpopulationen, dvs. när brottsligheten ökar så ökar fångpopulationen. Möjligheten att isolera effekter av fångpopulationen på brottsligheten stärks genom att Spelman använder så kallade instrumentvariabler. ${ }^{6}$ Av betydelse är också att Spelman har differentierat ${ }^{7}$ variablerna vilket Kovandzic och Vieraitis inte har gjort. 
När det kommer till effekter av fångtal på brottsligheten är emellertid Kovandzic och Vieraitis analys mer konservativ eftersom de analyserar den direkta effekten medan Spelman har använt interaktionen mellan fångtal och variabeln "metro" som antar värdet 1 för storstäder och värdet 0 för övriga. I Kovandzic och Vieraitis analys är, i och för sig, sambanden mellan fångtal och de sju indexbrotten negativa men ingen når gränsen för att vara statistiskt signifikanta, dvs. slutsatsen är att dessa estimat inte är skilda från värdet noll. Spelmans analys visar att både för tillgrepps- och våldsbrott är effekterna negativa och statistiskt signifikanta. För beslutsfattare, till exempel politiker, eller för den delen personer med traditionell kriminologisk utbildning är det inte lätt att veta vilken av dessa två studier som man ska luta sig mot. ${ }^{8}$

Hur ska dessa olika resultat förstås? Har fångpopulationens storlek ingen, en negativ eller positiv effekt på brottsligheten, med andra ord: minskar eller ökar antalet anmälda brott i samhället, eller har fångtalet ingen betydelse?

Liedka m. fl. (2006) har försökt att integrera resultat från kriminologisk forskning baserad på ekonometriska analyser av fängelsestraffets effekter på brottsligheten med mer traditionell kriminologisk forskning som hävdar att fängelsestraffet inte har några effekter eller rent av skadliga effekter på brottsligheten. I en statistisk modell prövas om sambandet mellan fångpopulation och brottslighet är negativt fram till en viss nivå för att därefter bli positivt. Undersökningsmaterialet avser samtliga amerikanska delstater för perioden 1972-2000.

Resultatet av analysen visar att elasticiteten mellan fångpopulationens storlek och brottsligheten är icke-linjär, dvs. sambandet ändrar riktning vid en viss nivå av fångpopulationen. När fångtalet överstiger 325 fångar per 100000 invånare övergår effekten från att ha varit negativ till att i stället bli positiv. Sambandet åskådliggörs i figur 1 nedan.

Den genomsnittliga amerikanska fångpopulationen var på 1970-talet 111 fångar per 100000 invånare. På 1980-talet hade den fördubblats och stigit till 207 och under 1990-talet återigen fördubblas till 397 fångar per 100000 invånare (Liedka m.fl., 2006, s. 269). En tolkning av detta resultat är därför att effekten av fångpopulationen på brottsligheten var negativ under 1970- och 1980-talet men under 1990-talet har den ökade fångpopulationen ett positivt samband med brottsligheten.

Shepherd (2006) menar i en replik till Liedka m.fl. att två omständigheter kan förklara varför den så kallade marginalnyttan av fängelsestraff på brottsligheten avtar när fångpopulationen överstiger en viss nivå. För det första beror ökningen av fångpopulationen i USA i stor utsträckning på att alltfler döms för narkotikabrott. Som grupp betraktad behöver de narkotikadömda inte vara särskilt kriminellt aktiva, enligt Shepherd. För det andra beror ökningen av fångtalen på att alltfler döms till längre fängelsestraff för mindre allvarlig brottslighet. Inte heller denna grupp gärningsmän behöver vara särskilt brottsaktiva. 
Figur 1. Sambandet mellan fangpopulation och brottslighet enligt Liedka m.fl. (2006)

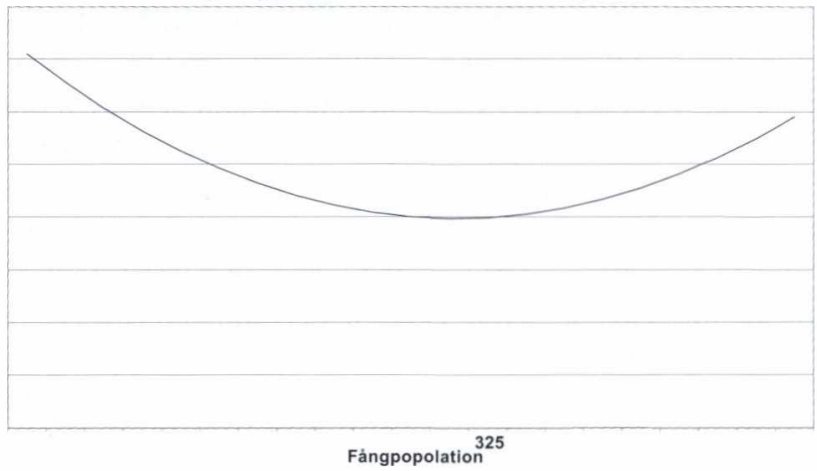

Sammanfattningsvis visar forskningen å ena sidan att personer dömda till fängelse löper en större risk för återfall i brott jämfört med matchade kontrollgrupper. $\AA$ andra sidan finns belägg för slutsatsen att fångpopulationen har ett negativt samband med brottsligheten dvs. att brottsligheten minskar när fångpopulationen, åtminstone till en viss nivå, ökar. Eftersom dessa resultat i huvudsak kommer från amerikanska studier där såväl brottsligheten men framför allt fångtalen skiljer sig från de flesta andra demokratiska länder är det oklart i vilken utsträckning detta samband också gäller för Europa.

\section{Hur ser sambandet ut mellan fångtal och brott i norden?}

Det har inte gått att finna några motsvarande empiriska studier av sambandet mellan fångtal och brott för länder i Europa. ${ }^{9}$ En förklaring kan givetvis vara att inget europeiskt land kommer i närheten av USA:s fångtal. Den officiella retoriken inom europeiska institutioner såsom Europarådet och EU, är för övrigt att fängelsestraffet har skadliga effekter för den enskilde fången såväl som för dennes familj. Inte heller för brottsoffer eller samhället i stort finns det några fördelar med fängelsestraff (Snacken 2006, s. 145). Ändå finns det ju där och under de senaste åren används det dessutom i större omfattning än tidigare. Möjligen är det som Balvig (2006, s. 110) tolkat opinionen att man "... ikke rigtig for alvor tror på" att straff inte skulle ha någon brottsförebyggande effekt.

I det följande beräknas, för det första, det statistiska sambandet mellan utvecklingen av fångpopulationens storlek och grövre våldsbrottslighet åren 1990-2005 för de nordiska länderna (Sverige, Danmark, Finland, Norge). Utgångspunkten för analysen har varit Spelmans (2000a, s. 486) rekommendation när det gäller att studera effekter av fängelsestraff: "We should also take seriously the obvious alternative - multinational comparisons". För det andra analyseras sambandet mellan fångtal och bostadsinbrott per månad i Sverige för två perioder, januari 1975 - december 1990 respektive januari 1994 - juni 2007. 


\section{Effekter av fångtal på grövre våldbrottslighet}

Som indikator på den grövre våldsbrottsligheten i de nordiska länderna används uppgifter om dödligt våld enligt dödsorsaksstatistiken. Det främsta skälet till att använda uppgifter om dödligt våld i stället för någon annan vanligare förekommande brottstyp är att det saknas jämförbar kriminalstatistik även mellan de nordiska länderna. Uppgifter om dödligt våld har hämtats från Världshälsoorganisationens (WHO) databas HFA-DB och avser personer i åldern 0-64 år som avlidit på grund av mord eller avsiktligt tillfogade skador (dråp). Endast Finland har redovisat uppgifter för hela perioden varför kompletteringar från de övriga ländernas nationella statistik har gjorts.

Den oberoende variabeln i analysen är fångpopulationen per 100000 invånare i respektive land. Dessa uppgifter har hämtats från nordisk statistik avseende kriminalvård (Kristoffersen, 2007).

Fem kontrollvariabler används i analysen: (i) den totala alkoholkonsumtionen, (ii) antal registrerade fall av hepatit B, (iii) andel arbetslösa, (iv) den procentuella ekonomiska tillväxten samt (v) regeringssammansättning (borgerlig eller socialdemokratisk). Dessa uppgifter har hämtats från WHO:s respektive $\mathrm{OECD:s} \mathrm{statistik}$ med vissa kompletteringar, medan uppgifter om regeringssammansättning hämtats från officiella källor. I tabell 2 sammanfattas dessa uppgifter för respektive land.

Tabell 2. Deskriptiv statistik 1990-2005.

\begin{tabular}{cccccccc}
\hline Land & $\begin{array}{c}\text { Dödligt } \\
\text { våld }\end{array}$ & Fångtal & $\begin{array}{c}\text { Alkohol- } \\
\text { konsum }\end{array}$ & $\begin{array}{c}\text { Hepatit } \\
\text { B }\end{array}$ & $\begin{array}{c}\text { Arbets- } \\
\text { löshet }\end{array}$ & Tillväxt & Regering \\
\hline Sverige & 1,17 & 65 & 5,9 & 2,7 & 6,8 & 2,0 & 0,2 \\
Norge & 1,04 & 61 & 4,6 & 3,8 & 4,5 & 3,1 & 0,5 \\
Danmark & 1,17 & 69 & 9,9 & 1,4 & 6,4 & 2,2 & 0,5 \\
Finland & 2,91 & 64 & 7,3 & 3,8 & 10,8 & 2,1 & 0,5 \\
\hline
\end{tabular}

Variabeln "Regering" är kodad $0=$ socialdemokratisk, 1 = borgerlig. Arbetslöshet och tillväxt $\mathrm{i}$ procent, övriga variabler per 100000 invånare.

Som framkommer i tabell 2 har Danmark haft den högsta alkoholkonsumtionen men det lägsta antalet personer infekterade med hepatit. Den genomsnittliga arbetslösheten har varit högst i Finland och lägst i Norge medan tillväxten har varit lägst i Sverige, även om skillnaderna är relativt små. I samtliga länder, förutom Sverige, har regeringarna i lika hög utsträckning varit borgerliga som socialdemokratiska.

Som framgår av figur 2 har det dödliga våldet i de nordiska länderna minskat sedan 1990-talet. Störst har minskningen varit i Finland där det dödliga våldet har minskat med en tredjedel mellan 1990 och 2005. Fortfarande är emellertid det dödliga våldet $\mathrm{i}$ Finland dubbelt så högt jämfört med övriga nordiska länder. Motsvarande positiva utveckling av det dödliga våldet märks även i ett flertal europeiska länder. 
Figur 2. Utvecklingen av dödligt våld i norden, 1990 - 2005

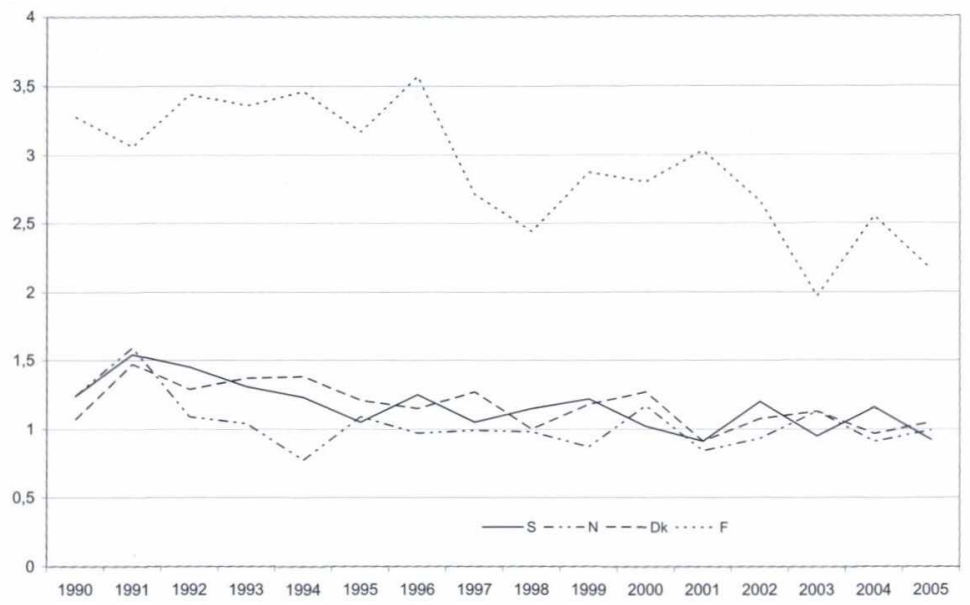

Även fångpopulationens utveckling är snarlik i de nordiska länderna. Sedan sluten av 1990-talet har fångtalen ökat i samtliga länder. Störst har ökningen varit i Sverige och lägst i Norge. Jämfört mellan 1990 och 2005 så har fångpopulationen i de nordiska länderna ökade med närmare 20 procent.

Figur 3. Utveckling av fångtalen i norden 1990 - 2005

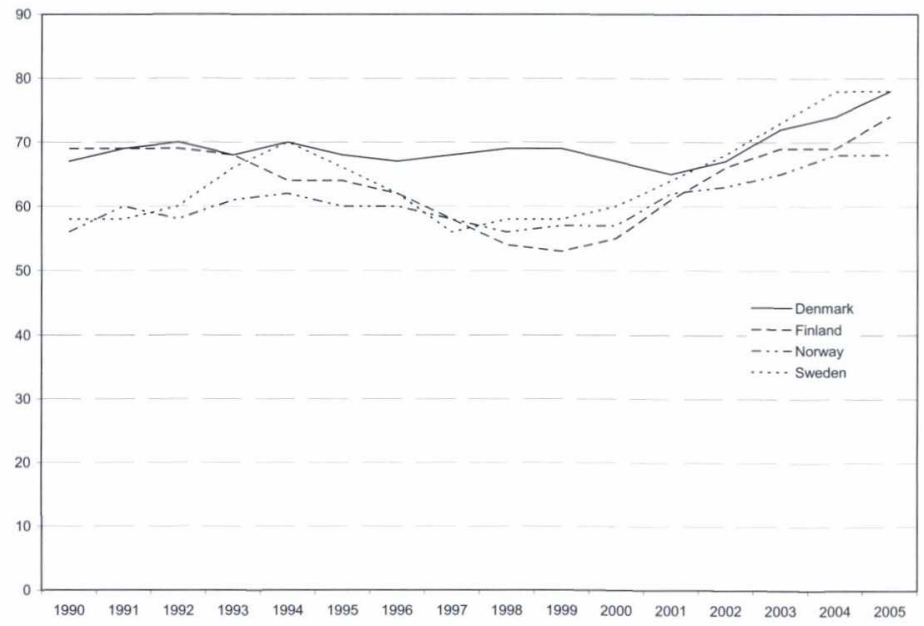




\section{Analysmetod och resultat}

Den centrala frågeställningen i denna analys är om utvecklingen av den grövsta våldsbrottsligheten har något samband med utvecklingen av fångtalen. Med utgångspunkt från den amerikanska forskning som redovisats tidigare är hypotesen att om fångtalet ökar så minskar brottsligheten, dvs. att sambandet är negativt. Syftet med att ta med vissa kontrollvariabler är att se om denna effekt uppkommer oavsett förändringar av socio-ekonomiska faktorer. För att undvika eventuella problem med ömsesidig påverkan mellan variablerna antas fångtalet ha en fördröjd effekt på brottsligheten. Den metod som används kallas omväxlande för "time-series cross-sectional analysis" eller "panel data analysis" och tillämpas inom såväl nationalekonomi som statsvetenskap och numera kriminologi (för en beskrivning av metoden se Worrall och Pratt, 2004; Levitt, 2001; Phillips och Greenberg, 2008).

I analysen undersöks om brottsligheten $\mathrm{i}$ land $i$ under år $t$ har ett samband med fångpopulationen $i$ landet året innan. I analysen tas hänsyn till förändringar av missbrukssituationen, arbetslösheten och den ekonomiska tillväxten samt till vilken politisk "färg" regeringen i respektive land har. Variablerna "dödligt våld" och "fångtal" liksom övriga variabler har logaritmeras så att koefficienterna anger elasticiteten.

Tabell 3. Effekter av fångtal på dödligt våld (time-series cross-sectional regression analysis)

\begin{tabular}{ccc}
\hline & Dödligt våld & Signifikansvärde \\
\hline Fångtal $_{\mathrm{t}-1}$ &,- 510 & 0,045 \\
Alkoholkonsumtion &, 008 & 0,971 \\
Hepatit B &, 047 & 0,055 \\
Arbetslöshet &, 051 & 0,287 \\
Ekonomisk tillväxt &,- 004 & 0,699 \\
Regering &,- 020 & 0,583 \\
\hline
\end{tabular}

Utöver dessa variabler inkluderas i analysen tre dummy-variabler för länderna och 15 dummy-variabler för åren.

Resultatet av analysen visar att en 1-procentig ökning av fångpopulationen minskar det dödliga våldet $i$ de nordiska länderna med igenomsnitt med 0,51 procent vilket alltså innebär att en 10-procentig ökning av fångpopulationen minskar det dödliga våldet med omkring 5 procent. Denna skattning är statistiskt signifikant och överenstämmer förhållandevis väl med amerikansk forskning. ${ }^{10}$ Av övriga variabler är det endast antalet fall av hepatit som har en statistiskt signifikant effekt. 
Analysen ovan baseras sammanfattningsvis på ett mycket begränsat material (64 observationer) och måste givetvis replikeras med data över en längre tidsperiod och möjligen för fler europeiska länder innan några säkrare slutsatser kan dras om sambandet mellan fångtal och dödligt våld.

I en kommentar till den analys som redovisats ovan menar von Hofer (2007) att det negativa sambandet mellan fångtal och dödligt våld under 1990-talet förefaller att vara temporärt, särskilt om man beaktar dessa två serier för perioden 1859-2004. En invändning mot detta skulle kunna vara att historiska data sällan har en sådan kvalitet att långa perioder kan användas till annat än grova analyser (såväl definitioner som insamlingsmetoder har givetvis förändrats under en 150årsperiod). I figur 4 redovisas utvecklingen över fångtal och dödligt våld i Sverige för perioden 1950-2005.

Figur 4. Utvecklingen av fängtal (heldragen linje med skalan till vänster) respektive dödligt våld per 100000 invånare i Sverige, 1950 - 2005. ${ }^{11}$

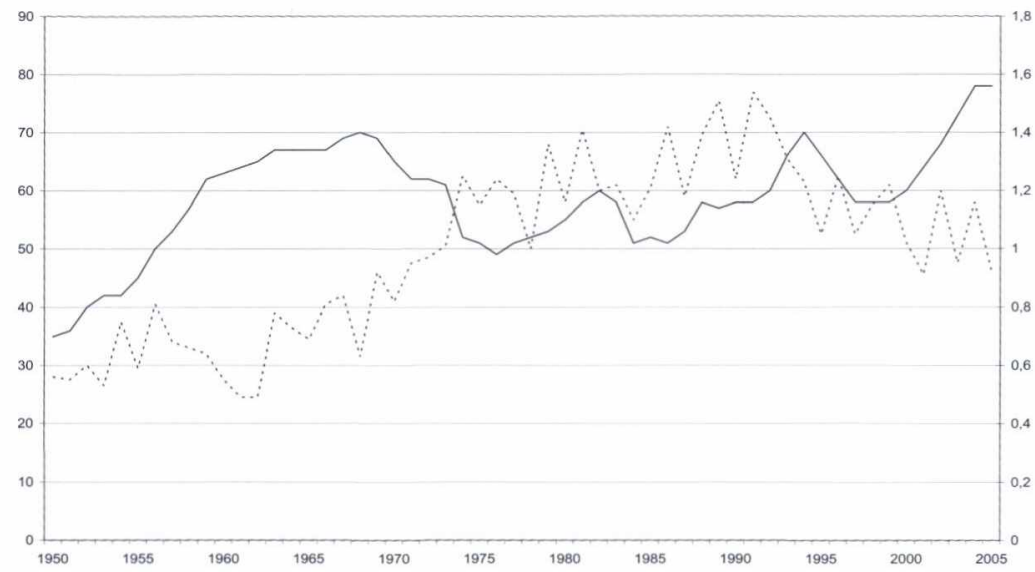

I en så kallad "cointegrated error-corrected time-series model"12 framkommer att sambandet mellan fångtal och dödligt våld är negativt för perioden 1950-2005. Även i denna analys uppgår effekten till $-0,5$ men signifikansnivån överstiger femprocentsnivån $(\mathrm{p}=0,08)$ vilket innebär att vi inte kan vara lika säkra på att effekten inte är skild från noll. På samma sätt som i den tidigare analysen innebär detta resultat att en tioprocentig ökning av fångpopulationen minskar det dödliga våldet efterföljande år med 5 procent. ${ }^{13}$

Slutsatsen att det finns ett negativt statistiskt samband mellan fångpopulation och dödlig våld behöver inte vara särskilt kontroversiellt och är möjligen helt ointressant. Översatt till konkreta siffror innebär dessa resultat att om den genomsnitt- 
liga dagliga fångpopulationen i Sverige ökar med 700 personer så kommer antalet fall av dödligt våld att minska med 5 efterföljande år. Intressant i sammanhanget är att mellan 1990 och 2005 minskade det dödliga våldet i Finland med 34 procent och fångpopulationen ökade med 7 procent. I Sverige ökade fångpopulationen med 34 procent medan det dödliga våldet minskade med 26 procent. I en nyligen publicerad rapport från Vera Institute of Justice konstaterar Stemen (2007, s. 5) när det gäller sambandet mellan fångtal och brott att: "Supporters take the findings as a confirmation that prison works... Opponents, on the other hand, see the findings as a confirmation that prison does not work very well at all".

\section{Effekter av fångtalen på bostadsinbrotten i Sverige}

I samband med Brå:s arbete med rapporten Brottsutvecklingen 1983 konstaterades att antalet bostadsinbrott ökat påtagligt jämfört med året innan (omkring 13 procent). Ökningen var särskilt markant andra halvåret 1983 jämfört med motsvarande period ett år tidigare. Ahlberg (1985) kom därför att undersöka om ökningen av antalet bostadsinbrott berodde på den i juli 1983 genomförda halvtidsreformen, dvs. ändringen i brottsbalkens 26 kap. angående verkställighet av strafftider. Ahlbergs slutsats var att omkring 800 av de beräknade 2700 bostadsinbrott som tillkommit under andra halvåret 1983 var en direkt konsekvens av reformen. Omräknat till procentuell förändring innebär Ahlbergs beräkningar ${ }^{14}$ att en 10-procentig minskning av fångpopulationen medför att bostadsinbrotten ökar med omkring 4 procent, dvs. en elasticitet på -0.4

\section{Figur 5. Antal anmälda bostadsinbrott per månad januari 1975 - juni 2007}

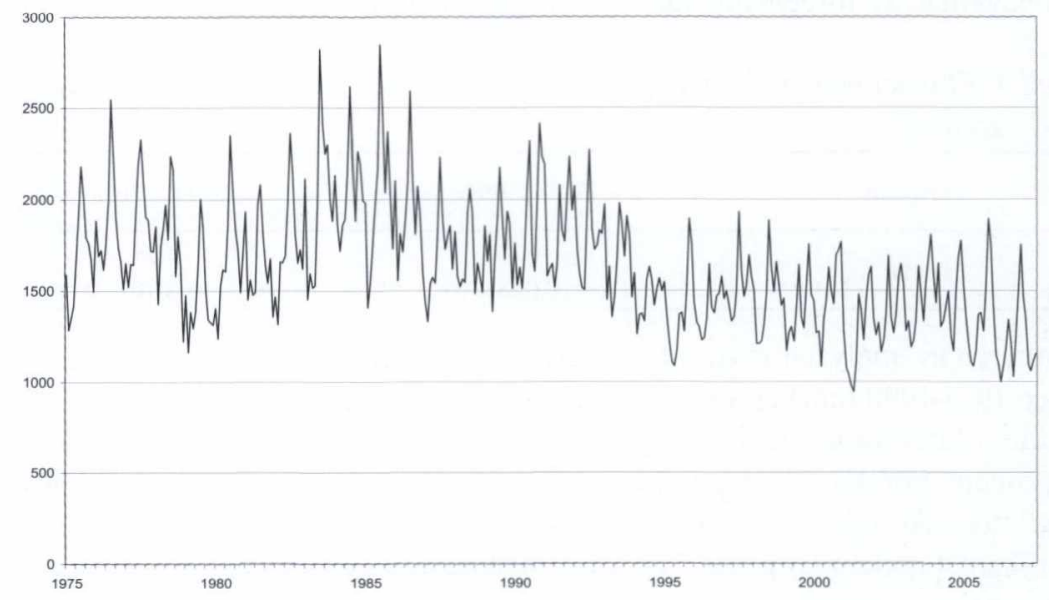


von Hofer (1993) redovisar i sin avhandling en närmare analys av om det går att dra några säkra slutsatser om halvtidsfrigivningens effekter på bostadsinbrotten. von Hofer konstaterar dels att ökningen andra halvåret 1983 i stor utsträckning skedde i den västra delen av landet, dels att en stor andel av personer som misstänktes för bostadsinbrott var unga $i$ åldern 15-20 år och inte äldre vanekriminella. Med hjälp av en tidsserieanalys för perioden januari 1965 till och med juni 1983 framkommer inte heller något negativt samband mellan förändringar i medelbeläggningen och bostadsinbrott. von Hofers slutsats är att Ahlbergs antagande om halvtidsreformens effekter på brottsligheten inte kan påvisas och att "bostadsinbrottens utveckling endast i liten utsträckning torde ha påverkats av fångtalets förändring” (von Hofer, 1993, s. 181).

Hur ser sambandet mellan fångtal och bostadsinbrott ut om man analysera månadsdata för perioden januari 1975 - december 1990 respektive replikerar en sådan analys för perioden januari 1994 - juli 2007? På grund av den stora statistikomläggningen 1975 är det mer lämpligt att ha detta år som startperiod..$^{15}$ I figur 4 redovisas antalet anmälda bostadsinbrott per månad för perioden januari 1975 till och med juni 2007.

I analysen nedan används en så kallad SARIMA-modell (seasonal, autoregressive, integrated, moving average) vilket innebär att sambandet mellan tidsserien över bostadsinbrott och tidsserien över fångpopulationen, med hänsyn tagen till att data uppvisar säsongsvariationer, beräknas. För att undvika problem med det möjliga ömsesidiga sambandet mellan dessa två serier används tidsförskjutna uppgifter om fångpopulationen. Det vill säga antalet bostadsinbrott månad $t$ antas vara påverkad av föregående månads fångpopulation.

Tabell 4. Elasticiteten mellan fångtal och anmälda bostadsinbrott (signifikansnivå inom parentes)

\begin{tabular}{ccc}
\hline Perioden & $1975-1990$ & $1994-2007$ \\
\hline Fångtal $_{t-1}$ & $-0,47$ & $-0,26$ \\
& $(0,028)$ & $(0,076)$ \\
\hline
\end{tabular}

Resultaten av analysen visar att en 10 procentig ökning av fångpopulationen perioden 1975-1990 innebär att antalet anmäla bostadsinbrott minskar med knappt 5 procent. Motsvarande analys för perioden $1994-2007$ ger en minskning på drygt 2,5 procent. För den första perioden är effekten statistiskt signifikant på konventionell nivå. Även för den andra perioden kan skattningen bedömas vara statistiskt signifikant. Sammanfattningsvis pekar denna beräkning på en negativ relation mellan fångtal och bostadsinbrott. Styrkan på sambandet överensstämmer dessutom väl med såväl amerikansk som australiensisk forskning (Weatherburn m.fl., 2006). 
En intressant fråga är, avslutningsvis, varför styrkan på sambandet mellan fångtal och bostadsinbrott i det närmaste har halverats i den senare perioden. Kan förklaringen möjligen vara att åldersammansättningen i fångpopulationen har förändrats? I Kriminalvårdens statistik redovisas dels antalet personer dömda till fängelse som intagits på anstalt under året, dels antalet inskrivna på anstalt vid ett bestämt datum. Under 2006 avtjänade 10428 personer ett fängelsestraff varav 826 personer ( 7,9 procent) var 55 år eller äldre. Den 1 oktober samma år var 5533 fängelsedömda inskrivna på anstalt varav 459 ( 8,3 procent) tillhörde gruppen äldre fångar.

Sedan 1996 har antalet äldre fängelsedömda som intagits under året ökat med mer än 30 procent men om man ser till antalet inskrivna den 1 oktober respektive år har antalet mer än fördubblats. Skillnaden beror på att alltfler äldre avtjänar ett längre fängelsestraff. Även i Sverige märks alltså en tydlig ökning av gruppen $55+$ bland de fängelsedömda. Enkelt sammanfattat ökade antalet äldre fångar med 32 procent mellan 1996 och 2006 medan antalet fångar under 55 år minskade med 16 procent. Det innebär att landets fängelseplatser allt oftare utnyttjas för äldre kriminella. Motsvarande utveckling har uppmärksammats i ett flertal länder (Crawley och Sparks, 2005).

Figur 6. Antal inskrivna i anstalt den 1 mars (1991-1995) resp. den 1 oktober (1996 - 2006) 55 år och äldre

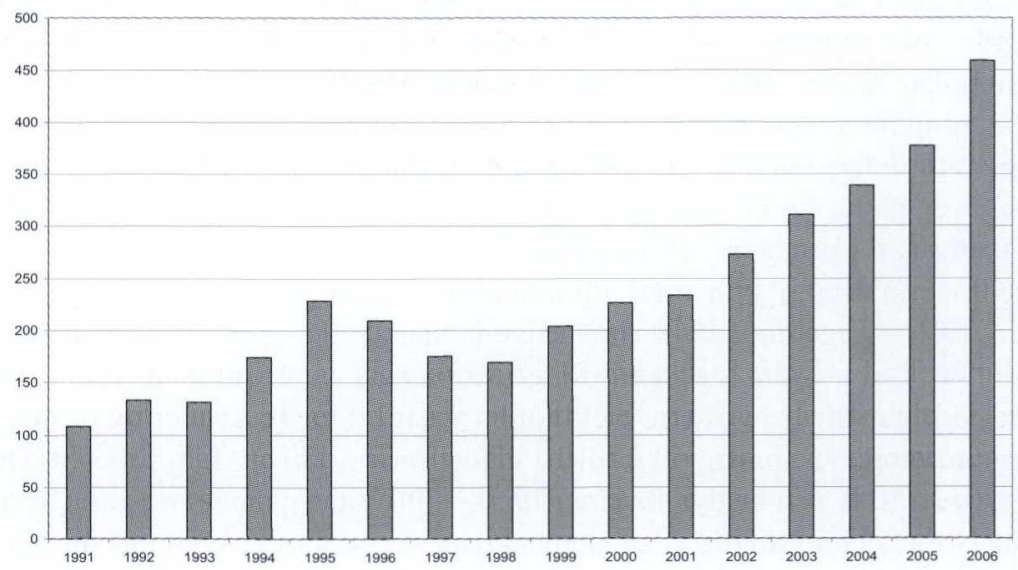

Inom den kriminologiska grundforskningen finns intresse för frågor om kriminella karriärer och påföljdssystemets utformning. I en unik engelsk longitudinell undersökning har drygt 400 personer (endast män) följts från 10-årsålder upp till 50- 
årsåldern (Farrington m.fl., 2006). Både uppgifter om självrapporterad brottslighet och brott som personen har registrerats för finns med i undersökningen. I en analys redovisas antalet självrapporterade brott vid olika åldersintervall bland de som också dömts för brott. I åldern 15-18 år uppger de som lagförts för brott att de begått $\mathrm{i}$ genomsnitt 48 brott per år. När personerna var i 27-32 års ålder var motsvarande antal 14 brott. När gruppen var i åldern 42-47 år uppgav de att de genomsnitt hade begått 4,5 brott per person och år. Fängelsestraff för den äldsta gruppen innebär med andra ord att samhället förebygger färre brott jämfört med om yngre skulle dömas till frihetsstraff. Samtidig är det som Kazemian och Farrington (2006, s 108) påpekar "... undesirable to incapacitate young offenders". En möjlig förklaring till att sambandet mellan fångtal och bostadsinbrott i Sverige minskar i styrka skulle alltså kunna vara att alltfler av de som döms till fängelse är äldre personer. Det kan tyckas märkligt att denna eventuellt dämpande effekt på detta samband inte har uppmärksammats i den amerikanska forskningen eftersom utvecklingen där vad gäller antalet äldre fångar är densamma.

\section{Slutord}

Det finns sällan enkla svar i samhällsvetenskaplig forskning i allmänhet eller i kriminologi i synnerhet. I denna artikel har presenterats aktuell forskning om fängelsestraffets effekt på brottsligheten. Såväl traditionell kriminologisk forskning som nyare ekonometriska analyser av denna frågeställning har diskuterats. Tre slutsatser kan dras utifrån litteraturen: (i) fängelsestraff tycks många gånger ha en negativ och skadligt effekt för den individ som dömts till ett sådan straff, (ii) på samhällsnivå kan fångpopulationens storlek emellertid minska brottsligheten, (iii) fångpopulationens storlek påverkas huvudsakligen av politiska beslut.

För att undersöka om det samband som framkommit i ett antal amerikanska studier även gäller för norden har för det första data från Sverige, Norge, Finland och Danmark för perioden 1990-2005 analyserats. För det andra har tidsseriesambandet mellan fångtal och antal anmälda bostadsinbrott i Sverige för perioden januari 1975 - december 1990 respektive januari 1994 - juni 2007 analyserats. Resultatet visar att förändringar i fångtalen har ett samband med förändringar av det dödliga våldet i norden. Relationen visar att en 10-procentig ökning av fångpopulationen minskar det dödliga våldet med omkring fem procent. Detta resultat bekräftas i en analys för åren 1950 - 2005 åtminstone avseende Sverige (i både Norge och i Finland är sambandet över tid svagare). Även mellan fångtal och bostadsinbrott föreligger ett statistiskt signifikant samband på ungefär motsvarande nivå, åtminstone under den första perioden. Däremot minskar styrkan på detta samband i den andra perioden. 
En möjlig förklaring till varför styrkan på sambandet mellan fångtal och bostadsinbrott i Sverige har minskat över tid kan vara att den åldersgrupp som allt oftare döms till fängelse (55 år och äldre) i stor utsträckning har sin brottskarriär bakom sig. Denna tolkning överensstämmer med Lippkes (2002, s 23) resonemang om att: "... policies of lengthy prison terms for serious crimes will generally be ineffective as a means of reducing crime once offenders reach their thirties". I en nyligen utkommen bok om fängelsestraffet konstaterar Lippke (2007, s. 265) vidare att:

\footnotetext{
"The logic of crime reduction requires us to weigh both the good and bad consequences of harsh imprisonment. The good consequences are less well established than many proponents of such imprisonment appear to believe, and the bad consequences are more numerous and worrisome than they appear to countenance".
}

Å ena sidan visar de analyser som gjorts i denna artikel att fångpopulationens storlek kan ha betydelse för brottsligheten på samhällsnivå. Å andra sidan finns gott om empiriska belägg för att fängelsestraff kan ha direkt skadliga effekter för den enskilde som döms och dennes närstående. Att utveckla metoder för att minska skadeverkningarna av straff - samtidigt som det i möjligaste mån förebygger brott - är minst sagt en angelägen kriminalpolitisk uppgift.

\section{Litteratur:}

Ahlberg, J. (1985). Effekter av halvtidsfrigivningen - Vad hände med brottsligligheten under hösten 1983? Brottsförebyggande rådet 1985:2.

Ahlberg, J. (1990). Inkapacitering. Effekter vid förändrade strafftider. Brottsförebyggande rådet 1990:7.

Andersson, J. (1991). Kriminella karriärer och påföljdsval. Project Metropolitan Research Report No. 35, Department of Sociology, Stockholms universitet Balvig, F. (2006). Virkninger af straf. I B. Kyvsgaard (red), Hvad virker - hvad virker ikke? Kunskabsbaseret kriminalpolitik og praksis. Jurist- og Økonomförbundets Forlag.

Becsi, Z. (1999). Economic and Crime in the States. Federal Reserve Bank of Atlanta, Economic Review.

Brå (2007). The Stockholm Criminology Symposium 2007. A Summary. Brottsförebyggande rådet.

Crawley, E. och Sparks, R. (2005). Old men in prison: survival, coping and indentity. I A. Liebling \& S. Maruna (red) "The Effects of Imprisonment. Willian Publishing. 
Farrington, D. P., Coid, J. W., Harnett, L. M., Jolliffe, D., Soteriou, N., Turner, R. E., \& West. D. J. (2006). Criminal careers up to age 50 and life success up to age 48: New findings from the Cambridge Study in Delinquent Development. Home Office Research Study 299.

Greenberg, D. F. (2001). Time Series Analysis of Crime Rates. Journal of Quantitative Criminology, 17:4, 291-327.

von Hofer, H. (1993). Fängelset. Uppkomst - avskräckning - inkapacitering. Tre kriminologiska studier. Kriminologiska institutionen, Stockholms universitet

von Hofer, H. (2003). Prison Population as Political Constructs: the Case of Finland, Holland and Sweden. Journal of Scandinavian Studies in Criminology and Crime prevention, 4, 21-38.

von Hofer, H. (2007). Current Swedish Prison Policy. I P O Träskman (red), Rationality and Emotion in European Penal Policy - Nordic Perspectives. Copenhagen: DJØF (under publicering).

von Hofer, H. (2007). E-post korrespondens samt bifogad analys av von Hofer, 2007-10-28.

Jacobson, M. (2006). Reversing the Punitive Turn: The Limits and Promise of Current Research. Criminology and Public Policy, 5:2, 277-284.

Kazemian, L. \& Farrington, D. P. (2006). Exploring Residual Career Length and Residual Number of Offenses for Two generations of Repeat Offenders. Journal of Crime and Delinquency, 43: 1, 89-113.

Kovandzic, T. V. och Vieraitis, L. M. (2006). The Effect of County-Level Prison Population Growth on Crime Rates". Criminology and Public Policy, 5:2, 213-244.

Kristoffersen, R. (2007). Nordisk statistikk for kriminalomsorgen i Danmark, Finland, Island, Norge og Sverige. Kriminalomsorgens utdanningssenter KRUS Lappi-Seppälä, T. (2000). The Fall of the Finnish Prison Population. Journal of Scandinavian Studies in Criminology and Crime prevention, 1, 27-40

Levitt, S. D. (1996). The Effect of Prison Population Size on Crime rates: Evidence from Prison Overcrowding Litigation. Quarterly Journal of Economics, May 1996.

Levitt, S. D. (2001). Alternative Strategies for Identifying the Link Between Unemployment and Crime. Journal of Quantitative Criminology, 17:4, 377-390.

Levitt, S. D. (2004). Understanding why Crime fell in the 1990s: four factors that explain the decline and six that do not. Journal of Economic Perspectives, 18:1, 163-190.

Liebling, A. och Maruna, S. (2005). Introduction: the effect of imprisonment revisited. I A. Liebling och S. Maruna (red), The Effects of Imprisonment. Willan Publishing. 
Liedka, R. V., Piehl, A. M. och Useem, B. (2006). The Crime-Control Effect of Incarceration: Does Scale Matter? Criminology and Public Policy, 5:2, 245276.

Lindström, P. (2006). Polisiär nolltolerans: Flipp eller flopp? Nordisk Tidskrift for Kriminalvidenskab, 93:1, 15-37.

Lippke, R. L. (2002). Crime Reduction and the Length of Prison Sentences. Law \& Policy, 24:1, 17-35.

Lippke, R. L. (2007). Rethinking Imprisonment. Oxford University Press.

Marvell T. B., och Moody, C. E. (1994). Prison Population Growth and Crime Reduction. Journal of Quantitative Criminology, 10:2, 109-140.

Marvell T. B., och Moody, C. E. (1997). The Impact of Prison Growth on Homicide. Homicide Studies, 1:3, 205-233.

Miles, T. J. och Ludwig, J. (2007). The Silence of the Lambdas: Deterring Incapacitation Research. Journal of Quantitative Criminology, 23:4, 287-301.

Murray, J., Janson, C-G., och Farrington, D. P. (2007). Crime in adult offspring of prisoners. A cross-national comparison of two Longitudinal Samples. Criminal Justice and Behavior, 34:1, 133-149.

Myrdal, G. (1969). Objectivity in social research: the 1967 Wimmer lecture, St. Vincent College, Latrobe, Pennsylvania New York: Pantheon.

Nilsson, R. (2003). The Swedish Prison System in Historical Perspective: a Story of Successful Failure? Journal of Scandinavian Studies in Criminology and Crime prevention, 4, 1-20.

O'Sullivan, E., och O'Donnell, I. (2003). Imprisonment and Crime Rate in Ireland. The Economic and Social Review, 34:1. 33-64.

Pager, D. (2003). The Mark of a Criminal Record. American Journal of Sociology, 108:5, 937-975.

Phillips, J. A. och Greenberg, D. F. (2008). A Comparison of Methods for Analyzing Criminological Panel Data. Journal of Quantitative Criminology, 24:1, 51-72.

Piquero, A. R. och Blumstein, A. (2007). Does Incapacitation Reduce Crime? Journal of Quantitative Criminology, 23:4, 267-285.

Pratt, T. C. och Cullen, F. T. (2005). Assessing Macro-Level Predictors and Theories of Crime: A Meta-Analysis. I M. Tonry (red), Crime and Justice: A Review of Research, vol. 32. Chicago: University Press.

Rosenfeld, R., Fornango, R., och Baumer, E. (2005). Did Ceasefire, Compstat, and Exile Reduce homicide? Criminology and Public Policy, 4:3, 419-450.

Shepherd, J. (2006). The Imprisonment Puzzle: Understanding How Prison Growth Affect Crime. Criminology and Public Policy, 5:2, 285-298.

Snacken, S. (2006). A Reductionist Penal Policy and European Human rights Standards. European Journal of Criminal Policy, 12:143-164. 
Spelman, W. (2000a). What Recent Studies Do (and Don't) Tell Us about Imprisonment and Crime. I M. Tonry (red), Crime and Justice: A Review of Research, vol. 27. Chicago: University Press.

Spelman, W. (2000b). The Limited Importance of Prison Expansion. I A. Blumstein \& J. Wallman (red), The Crime Drop in America. Cambridge University Press.

Spelman, W. (2005). Jobs or Jails? The Crime Drop in Texas. Journal of Policy Analysis and Management, 24:1, 133-165.

Spohn, C. och Holleran, D. (2002). The Effect of Imprisonment on Recidivism Rate of Felony Offenders: A focus on Drug Offenders. Criminology, 30:2, 329-358.

Spohn, C. (2007). The Deterrent Effect of Imprisonment and Offenders' Stake in Conformity. Criminal Justice Policy Review, 18:1, 31 - 50.

Stemen, D. (2007). Reconsidering Incarceration: New Directions for Reducing Crime. Vera Institute of Justice.

Wang, C. (1993). Sense and Nonsense of Statistical Inference. Controversy, Misuse and Subtlety. New York: Marcel Dekker.

Weatherburn, D., Hua, J. och Moffatt, S. (2006). How much crime does prison stop? The incapacitation effect of prison on burglary. Crime and Justice Bullin. Contemporary Issues in Crime and Justice, No. 93.

Westfelt, L. (2001). Brott och straff i Sverige och Europa. En studie i komparativ kriminologi. Kriminologiska institutionen, Stockholms universitet.

Worral, J. L. och Pratt, T. C. (2004). Estimation Issues Associated with Time-Series - Cross- Section Analysis in Criminology. Western Criminology Review, 5:1, 35-49.

Yaffee, R. (2000). Introduction to Time Series Analysis and Forecasting. Academic Press.

\section{Noter:}

1 En närmast dogmatisk uppfattning inom kriminologin det senaste decenniet är att endast kontrollerade experiment kan visa på orsakssamband. För en mer nyanserad syn på skillnaden mellan experiment- respektive observationsstudier se Wang (1993).

2 Med brottslighet avses i de amerikanska studierna vanligtvis s.k. indexbrott, dvs. mord, våldtäkt, rån, grov misshandel, inbrott, grov stöld och biltillgrepp.

3 Undersökningen är ännu inte publicerad. Citatet är hämtad från Brå:s sammanfattning av symposiet.

4 Pager (2003) har i ett experiment exempelvis visat att arbetssökande som uppger sig ha ett kriminellt förflutet är kraftigt diskriminerade på arbetsmarknaden. Experimentet gick ut på att två par män (två vita och två svarta) 23 år gamla sökte 350 lågkvalificerade arbeten (som städare, lagararbete, restaurangbiträde m.m.). Slumpvis fick den ena i paret uppge vid anställningstillfället att han var kriminellt belastad (dömd för narkotikabrott till 18 månaders fängelse), i övrigt 
var deras betyg och tidigare yrkeserfarenheter identiska (samtliga uppgifter var påhittade). Den vita mannen utan kriminell bakgrund erbjöds drygt vart tredje jobb som han sökte medan den vita mannan med kriminell bakgrund erbjöds 17 procent av jobben. En svart man utan kriminell bakgrund erbjöds 15 procent av de sökta jobben medan en svart man med kriminell bakgrund erbjöds 5 procent av de sökta jobben.

5 Det så kallade Projekt Metropolit respektive Cambridge Study of Delinquent Development.

6 En instrumentvariabel antas ha samband med den oberoende variabeln (fångtal) men inte med den beroende variabeln (registrerade brott) vilket gör att en mer renodlad effekt av den oberoende på den beroende kan skattas. Som instrumentvariabler använder Spelman bl.a. de samlade kostnaderna för rättsväsendet.

7 Eftersom tidsseriedata ofta är autokorrelerade, exempelvis årets fångtal har ett samband med fjolårets fångtal, så analyseras förändringar över tid (årets förändrade fångtal = årets fångtal - fjolårets fångtal).

8 De matematiska beräkningarna i Spelmans tidigare analyser av sambandet mellan fångpopulation och brottslighet kritiseras starkt av Liedka m.fl. (2006). I ett kapitel i den inflytelserika boken "The Crime Drop in America hävdar Spelman (2000b, s. 108) att "the prison expansion is responsible for reducing the violent-crime rate by 20 to 50 percent, with the best guess of roughly 35 percent". Samtidigt visar hans beräkningar att "violent-crime rates would have gone down in the 1990s even if prison population had not gone up... the hypothetical lines show that the drop would have come at almost exactly the same time, and been almost exactly the same size, as the actual drop". Liedka m.fl (2006, s 249) menar att denna slutsat "is an artifact of his method"(se vidare fotnot $8 \mathrm{i}$ denna artikel). Uppenbarligen är Spelman så fascinerad av sina statistiska resultat att han emellanåt gör kraftiga feltolkningar. Till exempel skriver han om effekten av "zero-tolerance policing", som finns med som en kontrollvariabel i analysen: "We can be 95 percent confident that a one-percent increase in public order arrests reduced property crime rate by 8 to 41 percent" (2005, s. 153). Att döma av tabell 6 i artikeln ska det vara att en 100 -procentig ökning, dvs. en fördubbling av public order arrest, ger sådana effekter. För andra slutsatser om polisiär nolltolerans se t ex Lindström (2006).

9 Det närmaste jag har funnit är en artikel av O'Sullivan och O'Donnell (2003) som utifrån Spelmans (2000b) antaganden om varierande elasticitetsmått mellan fångtal och brott har beräknat den hypotetiska brottsutvecklingen åren 1980-1999 på Irland om fångpopulationen inte hade förändrats. Deras slutsats är att: "While incapacitation undoubtedly has some reductive value in regard to crime against property, its impact on violent crime is debatable" (s. 58). Eftersom deras analys helt baseras på Spelmans (2000b) - vilket också gäller deras tolkningar av resultatet - menar O'Sullivan och O'Donnell (2003, s 57) att: "If not a pound had been spent on prison building the crime rate would still have fallen steeply". Att utvecklingskurvorna över den faktiska och den hypotetiska brottsligheten följer varandra i både Spelmans och O'Sullivan och O'Donnell analyser beror på att dessa serier rent matematiskt hänger samman. Det innebär att: "By construction, the historical time series of crime rates and Spelman's estimated time series must resemble each other" (Liedka m.fl, 2006, s. 250). För övrigt har O'Sullivan och O'Donnell räknat fel för våldbrottsligheten vilket gör att deras slutsats blir missvisande.

10 I Marvell och Moodys (1997, s. 228) analys framkommer att en 10 procentig ökning av fångpopulationen minskar det dödliga våldet efterföljande år med omkring 6 procent.

11 Data för perioden 1950 - 1997 är från Westfelt (2001).

12 Det är väl känt att genom differentiering försvinner information om en möjlig långsiktig relation mellan två tidsserier. Samtidigt är det lika känt att skattningar av sambandet mellan två ickestationära variabler kan ge missvisande resultat eftersom "... there is frequently a chance of a spurious correlation or spurious regression" (Yaffee, 2000, s. 420) därför att "classical statistical theory breaks down" (Greenberg, 2001, s. 300). Genom att beräkna en s.k. "error correction 
mechanism” är det möjligt att studera den mer långsiktiga relationen mellan två tidsserier i en konventionell tidsserieanalys.

13 När motsvarande analys görs för Finland respektive Norge erhålls en skattning på - 0,3 för båda länderna. Effekten är emellertid inte statistiskt signifikant.

14 Ahlberg redovisar inte särskilt mycket grunddata för sekundäranalys. Bostadsinbrotten ökade med 2800 brott mellan andra halvåret 1983 och genomsnittet för motsvarande period åren 1980-82. Ahlberg uppskattar att den "normala fluktuationen" är omkring \pm 800 brott. Den "onormala" ökningen andra halvåret 1983 blir därför ca 2000 brott varav omkring 800 av dessa, enligt Ahlberg, kan tillskrivas halvtidsreformen. Det innebär strax under 7 procentenheter av ökningen av bostadsinbrotten. Medelbeläggningen minskade med i snitt 5 procent andra halvåret 1983 jämfört med snittet för perioden 1980-82. En 10-procentig minskning av fångpopulationen leder således till en ökning av bostadsinbrotten med 4 procent $(7 / 5)$.

15 Mellan åren 1974 och 1975 ökade antalet registrerade bostadsinbrott med omkring 27 procent. Något som von Hofer lämnar utan kommentar.

\section{Adress:}

Växjö universitet

SE 35195 Växjö 